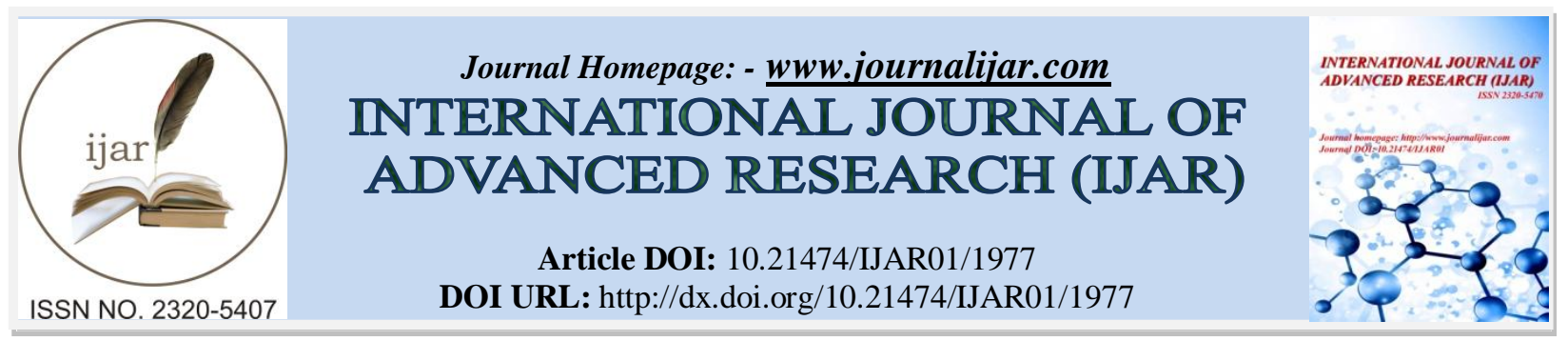

RESEARCH ARTICLE

\title{
A REVIEW OF CONDITION MONITORING ASSESSMENT OF POWER TRANSFORMERS INSULATION
}

\author{
Tanu Aggarwal ${ }^{1}$, Vishavdeep Jindal ${ }^{2}$ and Jashandeep Singh ${ }^{3}$. \\ 1. Research Scholar, Electrical Engineering Department, GZSCCET, Bathinda, Punjab Technical University. \\ 2. Electrical Engineering Department, GZSCCET, Bathinda, Punjab Technical University. \\ 3. Electrical Engineering Department, Bahra Group of Institutes, Patiala Campus, Patiala, Punjab, India.
}

\section{Manuscript Info}

Manuscript History

Received: 16 August 2016

Final Accepted: 22 September 2016

Published: October 2016

Key words:-

Power transformer, Insulation, mineral oil, Kraft paper, Alternative oils, natural esters, vegetable oil, mixed fluids.

\section{Abstract}

In regard to condition monitoring assessment of power transformers, so many techniques and researches have been carried out till date and some being under progress. The insulation of coils of a power transformer is employed by the Kraft paper and dipped in an insulating mineral oil. Both of these insulation terms demean with the passage of time as occurrence of fault so lead to decrease in efficiency of transformer. The paper is presented to show a widespread assessment of winding insulation provided by dielectric oil and paper. The intention is to present an extensive point of view on the winding insulation of power transformers which deals to find out an alternative to mineral oil in which paper degradation can be minimized and to characterize the Kraft paper. The presented references are broadly classified in the paper would provide rapid and practical relevance.

Copy Right, IJAR, 2016,. All rights reserved.

\section{Introduction:-}

Insulation is a broad-spectrum word, exercised to illustrate the means which can diminish gain or loss in heat by giving a solution as an obstruction between the fields that are considerably diverse in temperature. This insulation is an issue that is important if dealing with power transformers for efficient operation. To assess the aged condition of transformers and additional equipments installed in plant, a power plant should entail consistent methods. Occurrence of fault affects this insulation system and gives unreliable process.

Insulating media in high voltage transformers is generally made of solid paper enfolded around the windings, insulating oil usually mineral oil and pressboard in transformers to provide insulation to conductor from earth. The paper insulation provided on windings ought to be similar in temperament with oil used for insulation in tank and must not react chemically with it.

\section{Solid Paper Insulation:-}

The structure of Paper is prepared to form a leaf after melting and treating of a fiber. The untreated fiber materials are collected from plants. Thus unadulterated cellulose fiber is the wood pulp obtained by the process known as sulphite process. This is a technique to make a Kraft paper from wood pulp by processing with a range of salts having sulphurous acid which can be sulphites $\left(\mathrm{SO}_{3}{ }^{2-}\right)$ or bisulphites $\left(\mathrm{HSO}_{3}{ }^{-}\right)$to haul out lignin from the pulp. So it 
leads to formation of white liquor by entailing the pulping technique with sodium byproducts and result in splitting the chemical bonding between cellulose structure and lignin. This kind of Kraft paper is highly torn resistive, more elastic and breakdown strength, permeable and durable. The paper dipped in oil during vacuum conditions acquires sudden electrical breakdown strength. To find the applications of Kraft paper in distinct fields, permeability is an important consideration as the Kraft paper having high permeability is employed for casing the rectangle shaped $\mathrm{Cu}$ sheets and having moderate permeability is employed in layering the coil insulation or for bushings whereas the cable insulation is incorporated with crepe type of Kraft Paper.

\section{Liquid Oil Insulation:-}

In a high voltage transformer filled with liquid, an insulating oil acts as a key product for performing functional role of cooling by force out the produced thermal heat to ventilation system and to provide electrical insulation. But the insulation term does not matter in the transformers below $1000 \mathrm{~V}$ due to lower heat rejection. From a century, mineral oil obtained from fractional distillation process is practically preferred as the transformer oil worldwide due to ease of availability and higher fire point. The main tank of transformer is filled with this oil in which winding coils comprising with conductor and paper insulation are immersed. To fulfill the purpose of better transformer health and conditioning, following properties of insulating oil are considered to be appropriate with the actual standards.

Flash point is a temperature at which insulating transformer oil provides adequate vapors to form a combustible air blend which results into a spark under typical situations. This Flash point is a crucial property because it can give an idea about the probability of flame shoot. Thus higher the flash point, more the oil will be heat absorbent.

Pour point is the lowest heat point at which oil starts flowing under typical conditions. The transfer of heat to cooling system affects when temperature of the oil gets lowered than this particular standard value which reduces the efficiency.

Acidity in regard with transformer oil or neutralization number is the degree of measurement for evaluating the bitter elements of impurities. This is desired to reduce the effect of presence of acid contents in oil.

Dielectric strength of oil is also well-known as breakdown voltage of transformer oil. BDV is calculated by measuring the voltage at which arc struck between electrodes placed in oil alienated at some space. Lower Breakdown voltage shows the existence of water and conducting particles in oil.

Specific Resistance of oil is to determine the resistance of oil. It is an important parameter that is most sensitive with respect to temperature. Specific resistance of insulating oil reduces hastily with a small rise in temperature.

Dielectric dissipation factor is termed as loss angle. The tan delta is used to measure of tangent of angle between current and voltage which is displaced form $90^{\circ}$ when capacitive effect of dielectric is appeared.

Moisture content in insulating oil is extremely objectionable because insulating properties of oil get influenced. Paper used in solid insulation on windings aged at fast rate if it comes in contact with water. Paper soaks up surplus quantity of water present in oil due to which life of the solid insulation on windings is reduced as its dielectric properties get affected. Whereas if transformer is connected with load, then oil is heated up thus the solubility of water in oil get enhanced and paper liberates water so the water content in transformer oil is increased. Contact with oxygen results in production of acids in oil and this effect make the water more soluble in oil. This acid water mixture further decomposes the oil and oil degrades at speed.

Interfacial tension is a mean to observe force of attraction among oil water molecules. It is accurately valuable to find out the occurrence of pollutants or particles which lead to oil decomposition.

The condition monitoring assessment of insulation system of power transformers describes lifetime prediction of oilpaper insulation [1-3]. Extensive surveys have been carried out to monitor and diagnose the problem including laboratory experimental analysis to assess the condition of insulation used in transformers by regular maintenance [4]. These diagnostic techniques include fault gas analysis, moisture analysis, dielectric monitoring, UHF sensors, acoustic sensors, off line or on line PD testing, dielectric response measurements, time response dielectric spectroscopy, dielectric discharge method and return voltage measurement, interpretation of measurements, transfer 
function analysis and expert system diagnostic software. The phenomenon of understanding the ageing of Kraft paper insulation shows that paper degradation is the cause of production of furan based aldehydes or hydrocarbon gases produced in mineral oil which results in change in DP (degree of polymerization) of cellulose in insulating paper or effect of various parameters using electrical, mechanical and chemical techniques is evaluated which are relevant to assess the state of both paper and oil insulation with identifying its effective life [5-20]. Thermal degradation of Kraft paper is caused due to increase in operating temperature so this insulating paper is thermally upgraded to neglect the aging by treating it with additional additives which result in formation of a new modified insulating paper such as amine modified Kraft paper, cyan ethylated paper, and carbamate modified paper by chemical modification for better performance and some other alternative oils are used as a substitute to mineral oil like alkyl-naphthalene oil, vegetable oil to increase the life of oil- paper insulation [21-22]. Mineral oil, mostly used liquid dielectric in power transformers is a main concern because of presence of poly-nuclear aromatic hydrocarbons which are not specific for insulating paper so a considerable work have been done to find an alternative liquid dielectric for power transformer for improving the oil immersed insulating paper condition[23-91]. Various alternative oils such as natural esters, vegetable oils, $\mathrm{LN}_{2}$, coconut oil, palm oil and many more has been experimented and has given better results for paper aging condition as compared to hydrocarbon oils.

The ambition of this paper is to provide a wide-spread review in the field of oil and paper insulation assessment in power transformers. All the referred publications are listed and presented in three categories. First division concerns with the subjects of condition monitoring of power transformers, review on monitoring condition of transformer and different diagnostic techniques, measurement and knowledge for aging of Kraft paper, effects of various parameters like air, water content, temperature, change in frequency, burden and air pressure on physical, chemical and insulating properties of paper, problems assassinated with Kraft paper like deposition of copper sulphide, presence of methanol in oil, formation of furan particles which assist degradation and their suppressive effects, thermal up gradation of paper by chemical modification to improve its condition[1-25]. Second and third categories include replacement to mineral oil by another liquid dielectrics covers an alternative liquid dielectrics having esters, vegetable oils in place of mineral oil and their comparative studies, palm oil and coconut oils and challenge of using mixed liquid dielectrics for high voltage transformers[26-93].

The presentation of paper is done in five segments; First segment is about introduction whereas remaining segments depict aging effect, methods employed to assess the state of insulation, Alternatives provided to mineral oil and concluding remarks.

\section{Ageing Effects:-}

Insulation aging is an undesirable phenomenon which decreases the healthy life of a transformer. The force surrounds the insulation whether it is oil or paper insulation resulting in degradation. This force can be appeared in any form of stress like heat, pressure, electrical or chemical stress which reduces the bonding strength of molecules in oil and paper and decompose them. These stresses show the way to dreadful condition of oil and cellulose. Various factors are responsible for deterioration of oil-paper insulation as described below.

Cellulose structure is made of series of molecular bonds. This series of binding is a measure of DP (degree of polymerisation) of paper. Generally a cellulose paper should have DP value greater than 1000, but degradation of paper breaks the molecular bonds present between chains which resulting decrease in DP value. If the DP value lowers to 200 then paper is no more to use as an insulator because at that point it can be easily broken and its strength is completely goes away [21].

This breakdown process of molecular chains in cellulose paper produces $\mathrm{H}_{2} \mathrm{O}$ particles which go through the oil and appear as a channel between both insulations. This migration of water from paper to oil results in reduction of dielectric strength of oil with increase in moisture. The whole structure of cellulose consists of hydrogen and hydroxyl bonds at each spot. The flow of water to these spots upset the bonding chains and weakens the cellulose structure. Initially, the moisture content in insulating cellulose paper is negligible and it take up a low amount just 5$6 \%$ from oil in its initial stage to maintain the balance between oil-paper combination. If the cellulose is more hydrated than oil in which it is immersed and its surrounding air then water is taken up by oil and air from paper or vice versa. With the decrease in temperature, the moisture absorption capacity is also reduced because oil becomes more viscous at cold temperature and hinders its circulation through cellulose [14]. 
Another factor the breakdown voltage of oil paper insulation system in transformer is raised up if heat point is low. Crepe discharge occurs at highest temperatures due to which structure of cellulose degraded and its electric strength reduces. Thickness is one more important parameter which affects the breakdown capacity. The paper more in thickness has more breakdown capacity but it lowers with increase in temperature. Measurement beyond $170^{\circ} \mathrm{C}$ is not possible because paper separates into tiny portions. Electric strength obtained is approximately 13, 12, $11 \mathrm{KV}$ for $110^{\circ} \mathrm{C}, 130^{\circ} \mathrm{C}, 150^{\circ} \mathrm{C}$ respectively $[23]$.

It is observed that presence of oxygen lowers the oxidation stability of oil, deteriorates oil and form acids. Due to presence of acid contents, cellulose paper composition gets damaged. Carbon-di-oxide, carbon-mono-oxide, water content, free glucose and acids are the instant derivatives produced as a result of paper degradation. Water contents produced in oil and acid formation additionally humiliate the glucose into 5-hydroxymethyl-2-furfuryl (5H2F). This aldehyde by-product is not a balanced complex so immediately rot into various furaldehydes (furans) comprising 5methyl-2-furfuryl (5M2F), furfury alcohol (2FOL), 2- acetyl furan (2ACF) and 2-furaldehyde (2-FAL) [15].

In addition, a product DBDS (Dibenzyl disulfide) found in mineral oil which causes the layering of copper sulphide on cellulose insulating material [9]. This deposit layer on paper increases rate of deterioration of paper. Thus Sinking the DBDS amount present in liquid dielectric is very effectual for suppressing the layering of copper-sulfide [10]. It is required to minimize the presence of DBDS compound in oil to increase the life span of a transformer. Thus poorer degradation of paper engrossed in alternative oils than conventional mineral oil increases the DP of paper and life time of transformer.

Among solutions to degradation of winding insulation problems and to improve thermal ageing characteristics of paper, thermally upgraded Kraft paper is adapted by addition of additive like N-butyl carbamate with nitrogen content aged at temperatures $130-170^{\circ} \mathrm{C}$. In this modified paper contamination of transformer oil due to paper is less as compared to Kraft paper [23].Thermal ageing of Kraft paper can also be reduced by using alkyl-naphthalene oil because thermal degradation products found in alkyl-naphthalene oil are not as much of conventional mineral transformer oil [24]. Thus by modification with definite nitrogen compounds, susceptibility to thermal degradation can be transformed. The adding up of preservative suppresses the temperament of ageing progression as it reacts chemically with paper which is to be degraded.

\section{Methods Employed to Assess State of Insulation:-}

Till date a number of techniques are discussed by various researchers and experts in the field of insulation of power and distribution transformers $[6,90-91]$. Various methods described in earlier researches are still exercised by power industries to minimize degradation and aging. These methods comprise measurement of partial discharges (PD), insulation resistance (IR), dielectric dissipation factor, interfacial polarization (IP) using IR and frequency dispersion of capacitance, oil quality, moisture content, dissolved gas analysis (DGA), polymerization value (DPv) of insulating paper. Others are relatively new ways over the last two or three decades, including high performance liquid chromatography (HPLC) furan analysis and Interfacial polarization spectrum (IPS) by return voltage measurements etc.

\section{Dissolved Gas Analysis:-}

The DGA is a powerful method which can significantly identify the condition of transformer. This procedure is widely used to find out the inner faults in operational transformers. In Gas chromatography, the fault identification is totally based upon the type and amount of hydrocarbon gases which present in oil under faulty conditions. So to analyze the dissolved gases by D.G.A is a trustworthy procedure to diagnose the healthy condition of transformer whose operation has been restricted by assumed false operation of differential protection as there may be inrush current or problem appeared due to wrong C.T. connections and suction difficulties in Buchholz relay can be removed and it can be in service back with more assurance on the basis of DGA outcomes [61].

\section{Frequency Response Analysis:-}

Frequency Response Analysis is analyzed to spot the faults which have an effect on impedance of transformer and also helpful to detect winding movement [6].

In Sweep Analysis of FRA, two sweep frequency responses are compared; analyzed and any considerable difference in regions of low frequency, change of existing resonance, conception of new resonance, altering the shape of plot would tell about a problem incurred with in winding and core of transformer whether it would be a mechanical or electrical fault type. With any type of structural damage in transformer, frequency response will lead to change in 
RLC network and by using FRA technique these changes in RLC network are tinted and problem is identified with in the transformer. The insulating system has never uniform electrical stress. Materials having low dielectric current get highly stressed. An increase in the stress beyond a specified limit results in partial insulation failure. So the discharge appeared in the part of insulation system is termed as partial discharge. Partial Discharge is a cause of inappropriate design and service provided to the transformer. It is not a term related with discharge directly between two electrodes. PD will result in production of various insignificant problems like gas suds are produced in oil and discharge trees are formed in paper which decreases the dielectric strength of insulating system [4].

\section{Furan Analysis:-}

Furan analysis is used to detect the breakdown of solid insulation i.e. paper insulation due to high temperatures, moisture and oxygen present in oil and paper. If furan test is used with DGA analysis, it is proved to be best method to analyze the absolute condition of transformer. This analysis determines amount of paper degradation when it dissolved in oil. It indicates that there is presence of carbon and hydrogen compounds. The transformer is nearer to failing condition when furan result exceeds $2500 \mathrm{ppb}$. It is basically important to decide that when to replace an operational transformer working from many years with a new one [8].

A rough estimation about life of insulation is that, for every $6^{\circ}$ to $8^{\circ}$ Celsius rise in normal temperature of operation, it get approximately halved. Furans produced from this temperature rise affect the insulation by two ways: the first is the damage of paper insulation by local area heating, and the second is heating of complete insulation system.

Acids are produced and get reacted with insulation system and metallic structure which result in the formation of soaps and more acids, causing a sadistic cycle. Oxygen inhibitor is required element for enhancing the life of transformers. The inhibitor presently in use is Ditertiary Butyl Para cresol (DBPC). This works like a sacrificial anode in grounding circuits and protects the insulation as oxygen react with inhibitor added instead of the insulating paper. When the transformer gets aged and the inhibitor is exhausted thus needs to be replaced. With replacement of the inhibitor it requires that the oil filled should also be treated.

\section{Corrosive Sulphur:-}

Corrosive sulphur is a rickety and thermally unstable compound dissolved in oil which corrodes the copper and metallic parts of transformer. This sulfur is appeared as a compound DBDS (Dibenzyl disulfide) found in mineral oil that causes the deposition of copper sulphide on paper insulating material. When sulphur present in DBDS comes in contact with copper leads to layering of copper-sulphide on insulating paper due to which electric strength of insulation is reduced [9]. Decreasing the DBDS value partially in mineral oil will enhance life span of transformers [10].

\section{Dielectric Dissipation factor:-}

Electrical stress is also a major concern for insulation degradation. Every electrical device endures stress from mechanical vibration, in service voltage, rise in temperature, gaseous and solid metallic impurities. These stresses will lead to degradation of insulation by gradual ageing of the equipment parts and at times it will result to avalanche of Insulation breakdown. In the whole power system ageing of small insulation may cause terrible collapse of the system, leading to intense failure. It is desired to be familiar with the specified feature of insulation required for the particular device used in the power system to avoid these types of surprising collapses and for continuous service. Also it is necessary to monitor the insulation properties of all major equipments installed in power system from time to time [4].

\section{Metal Analysis:-}

This is used to set off dissolved gas analysis. When DGA is applied to find out the presence of possible fault, then metal analysis will indicate which type of fault is present and where it is located. Severe faults not just degrade the oil and solid insulation of transformer but also lead to production of metal particles that go away with oil. As the oil circulates, these metals will be disseminated all over the transformer. Some of the components of transformer machinery produce certain kind of metal particles which can be found unaided or a composition of different metals based upon the type of fault. Depending upon the composition and concentration of these metals present in system will give an idea to find out which metal component is involved in which kind of fault. 


\section{Insulation Resistance:-}

This test is helpful in identifying mechanical irregularities and impurities in the dielectric (may appeared during manufacturing) due to which insulation get affected. Insulation resistance should be high reliable with satisfactory insulating properties. The test is employed when connections are loose or there occur an undesired ground. To test for unplanned core grounds, take away the planned ground and Megger between the core and the grounded transformer tank. By using this test, a very high resistance will be provided which indicate that an unplanned ground is not in system. This test is done in addition to DGA that describes the production of gases and to point out the problem resulting from an unintentional core ground.

\section{Alternatives to Mineral Oil:-}

The liquid dielectric mineral oil used in transformers from many years is preferred usually because it can be used for both purposes as a coolant and an insulator, has better characteristics, easily available, less costly, and the main property is that it is freely compatible with insulating Kraft paper. But the major issue is paper degradation which increases as the temperature increases. So in regard to it various alternatives are provided from time to time for improving paper condition and transformer operation.

Ester fluids are proven to be a better alternative of mineral oil because fire points and flash points of Esters are more than mineral oil thus safe to use in transformers as insulating oil. Instead of that Ester fluids are readily biodegrade than mineral oils [27-53]. The synthetic esters give up ethylene upon aging whereas natural esters give way to hydrogen and ethane. In addition, at temperatures more than $130^{\circ} \mathrm{C}$, the aging of cellulose in synthetic esters or mineral oil is more than that experimental in natural esters [46].Also paper ageing in natural ester gives lesser amounts of $\mathrm{CO}, \mathrm{CO}_{2}, 2-\mathrm{FAL}$, and 5- $\mathrm{HMF}$ as compared to synthetic and mineral oils. Despite the higher viscosity of natural esters, they possess higher gravity and heat than mineral oil.

Vegetable Oils are triacylglycerols. These are the products obtained by estrification of glycerol by fatty acids [5491]. Vegetable oils with lower poly instauration show better oxidation stability. These oils are suitable substitute of mineral oil in low electrical energy applications. Below $130^{\circ} \mathrm{C}$, the paper gets aged at faster speed in vegetable fluids as compared to mineral oil. However, above $130^{\circ} \mathrm{C}$, the quantity of furaldehyde products in it is less than in mineral oil. Similarly these oils possess large degree of polymerization values for cellulose insulation rather than mineral oils which shows the paper exploitation in vegetable oil is less [54-65]. The fatty acids produced in this oil with the reaction of water are transestrified by $\mathrm{OH}$ ionic compounds present in paper which prevents the paper deterioration. The speed of prevention of paper from deterioration is fast. The second reason for less paper aging in vegetable oil is due to a layering of paper with a thicker jelly type element which is produced as a result of aging of vegetable oil. This substance provides protection to the paper commencing aging as a safeguard of cellulose material.

Coconut Oil consist liberated fatty acids and are more conductive because of it. Refined Bleached and Deodorized (RBD) coconut oil is well again suitable for the replacement of transformer oil as compared to all its natural forms copra and virgin coconut oils available commercially. However there are some inadequacies found in its substantial behavior but still it is a better option [49].

Jatrophacurcas Seeds Oil can also be referred as an alternative to transformer oil in some research works done earlier [71]. This Jatrophacurcas oil is a non food crop. Jatrophacurcas oil is routed by catalytic estrification technique by means of potassium hydroxide to generate JMEO (jatrophacurcas methyl ester oil) whose viscous and acidic point is suitable for high power applications particularly in transformers. This oil type possess numerous benefits that suggest equally its making and practice than other vegetable oil types as palm oil and rapeseed oil as these crops are mature on sullied and trivial soil which avoid the use of more productive lands which are currently in use by some farmers to cultivate their crops. It will willingly nurture in regions where yearly precipitation levels are appreciably lesser than requisite by other vegetable oil species. For instance, this vegetation can unproductive lands are set up in various areas of eastern regions that stay intact because of the obscurity placed in the ground with different vegetation types.

Mixed Fluids are used as transformer oil by mixing two or more oil types to provide a better oil type. In earlier times, mineral oil is the only oil which could be used as insulating liquid dielectric fluid in power transformers. The reason for which mineral oil is not environment friendly is its no biodegradability. So to avoid or to conquer the difficulties arose in mineral oil, vegetable oil is found as a replacement for transformer mineral oil. These alternative fluids are considerably better biodegradable and are more compatible to the environment. In addition to this, the 
refined natural esters, synthetic esters and vegetable oils are selected and can be mixed in desired amounts. Thus mixed fluids obtained by this procedure gives higher values of dielectric strength as compared to other fluids [92, 93].

\section{Concluding Remarks:-}

An extensive review of conditioning assessment for insulation in case of power transformers is accessible to make available a comprehensible point of view on a variety of characteristics of these techniques to the research holders, assistant engineers and commercial manufacturing industrialists. The winding insulation degrades due to presence of furan degradation products in mineral oil which are not specific for the paper condition. According to various referred publications it is clear that need of alternative oils is due to inability of mineral oils to biodegrade easily. Due to which various biodegradable oils are used in place of non biodegradable conventional oils which improve the paper condition hence lifetime of power transformers.

\section{References:-}

1. A.Basak, "Condition monitoring of power transformers", Eng. Sci. Educ. J., vol. 8, no. 1, pp.41-46, 1999.

2. H. Herman, M. J. Shenton, et al., " a new approach to condition assessment and lifetime prediction of paper and oil used as transformer insulation”, in proc. 2001 IEEE 7th Int. Conf. Solid Dielect., pp. 473-476, 2001.

3. A. Granitschnig and W. Seitlinger, "Transformer Performance assessment," in Proc. 14th Int. Conf. Dialect. Liquids, Graz (Austria), pp 317-320, July 2002.

4. Barry H. Ward, "A Survey of new techniques in insulation monitoring of power transformers" IEEE Electr. Insul. Mag., Vol. 17, no. 03, pp. 16-23, May/June 2001.

5. M. Ali, C. Eley, A.M. Emsley, R. Heywood, and X. Xaio, “ Measuring and Understanding the ageing of Kraft Insulating Paper in power transformers”, IEEE Electr. Insul. Mag., Vol. 12, No. 3, pp. 28-34, May/June 1996.

6. M. Darveniza, D.J.T. Hill, T.T. Le, "Investigations into effective Methods for assessing the condition of Insulation in aged power transformers", IEEE Trans. Pow. Del., Vol. 13, No. 4, October 1997.

7. V.T. Morgan, "Effect of frequency, temperature, compression, and air pressure on the dielectric properties of a multilayer stack of Dry Kraft Paper", IEEE Trans. Dielectr.Electr. Insul, Vol. 5, No. 1, pp. 125-131, February 1998.

8. R.M. Morais, W.A. Mannheimer, M, Carballeira, J.C. Noualhagu, "Furfural Analysis for assessing degradation of thermally upgraded papers in transformer insulation", IEEE Trans. Dielect. Electr. Insul. Vol. 6, No. 2, pp. 159-163, April 1999.

9. T. Amimoto, N. Hosokawa, "Concentration dependence of corrosive sulphur on copper- sulfide deposition on insulating paper used for power transformer insulation”, IEEE Trans. Dielectr. Electr. Insul. , Vol. 16, No. 5, pp. 1489-1495, October 2009.

10.T. Amimoto, F. Kato, R. Nishiura, "Suppressive effect and its duration of triazole - based passivators on copper sulfide deposition on Kraft paper in transformer”, IEEE Trans. Dielectr. Electr. Insul. , Vol. 20, No. 5, pp. 19151921, October 2013.

11.S. Y. Matharage, Q. Liu, Z. D. Wang, P. Mavrommatis, G. Wilson, “Ageing assessment of transformer paper insulation through detection of methanol in oil", presented at IEEE $11^{\text {th }}$ Int. Conf. Properties and Applications of Dielectric Materials (ICPADM), 2015 .

12.D. Linhjell; U. Gafvert; L. E. Lundgaard, "Dielectric response of oil-impregnated paper insulation: variation with humidity and ageing level [power transformer applications]", presented at Annu. Report Conf. Electrical Insulation and Dielectric Phenomena, CEIDP '04, 2004

13.G. L. Atkinson; W. R. Thomas, "An Epoxy-Paper Insulation System for High-Voltage Applications" IEEE Trans. Dielectr. Electr. Insul. , Vol. EI-2, Issue 1, pp. 18-24, 1967.

14.I. Sutan Chairul; S. AbGhani; M. S. Ahmad Khiar; Y. H. Md Thayoob; Y. Z. Yang Ghazali, "Kraft paper insulation's life assessment and effects of oxygen and moisture to paper insulation's deterioration rate", presented at IEEE Int. Conf. Power and Energy (PECon), 2012 .

15. Unsworth J., Mitchell F., "Degradation of electrically insulating paper monitored with high performance liquid chromatography”, IEEE Trans. Dielectr. Electr. Insul., Vol. 25, No. 4, pp. 737-746, August 1990.

16.B. Pahlavanpour; M. A. Martin's; A. De Pablo, "Experimental investigation into the thermal-ageing of Kraft paper and mineral insulating oil”, presented at Conf. Rec. of IEEE Int. Symp. Electrical Insulation, 2002. . 
17.Piotr Przybylek, Hanna Moscicka-Grzesiak, "The influence of water content and ageing degree of paper insulation on its mechanical strength," presented at $10^{\text {th }}$ IEEE Int. Conf. Solid Dielectrics (ICSD), 2010 .

18. Nick Lelekakis, Daniel Martin, Jaury Wijaya, "Ageing rate of paper insulation used in power transformers Part 2: Oil/paper system with medium and high oxygen concentration”, IEEE Trans. Dielectr. Electr. Insul., Vol. 19, Issue 6, 2012,

19. Robert R. Buntin, Robert D. Wesselhoft, Eric O. Forster, "A Study of the Electrical Insulation Characteristics of Oil-Impregnated Polypropylene Paper “,IEEE Trans. Dielectr. Electr. Insul. , Vol. EI-7, Issue 4, 1972.

20.M. C. L. Lessard, M. Masse, "Prediction of remaining life of the paper insulation by the analysis of new oilsoluble compounds in power transformers", presented at Annu. Report Conf. Electrical Insulation and Dielectric Phenomena, 2003.

21.Enis Tuncer; Georgios Polizos, Isidor Sauers, D. Randy James, "Electrical Insulation Paper and Its Physical Properties at Cryogenic Temperatures", IEEE Trans. Appl. Supercond. , Vol. 21, Issue 3, 2011.

22.T. Leibfried and A. J. Kachler, "Ageing and moisture analysis of power transformer insulation system", published at CIGRE Session, Paris, 2002

23. Akira Miyoshi, "A new Additive for improving the thermal Aging characteristics of Kraft Insulating Paper", IEEE Trans. Electr. Insul., Vol. E1-10, No. 1, pp. 13-16, March 1975.

24. Akira Miyoshi, "A Method for thermally upgrading Insulating paper using Alkyl- Naphthalene Oil", IEEE Trans. Electr. Insul, Vol. E1-11, No. 3, pp. 72-75, September 1976.

25.R. D. Villarroel; D. F. García; M. A. Dávila; E. F. Caicedo, "Particle swarm optimization vs. genetic algorithm, application and comparison to determine the moisture diffusion coefficients of pressboard transformer insulation", IEEE Trans. Dielectr. Electr. Insul., Vol. 22, Issue: 6, 2015.

26. M. Jovalekic; D. Vukovic; S. Tenbohlen, "Dissolved gas analysis of alternative dielectric fluids under thermal and electrical stress", presented at IEEE Int. Conf. Dielectric Liquids (ICDL), 2011.

27.Fernando Delgado; Alfredo Ortiz; Inmaculada Fernandez; Alberto Arroyo; Jose Antonio Macías, "Study on the cooling capacity of alternative liquids in power transformers", presented at Int. Conf. Electrical Systems for Aircraft, Railway and Ship Propulsion (ESARS), 2012

28. Jiri Ulrych; Michal Svoboda; Radek Polanský; Josef Pihera, "Dielectric analysis of vegetable and mineral oils", presented at $18^{\text {th }}$ IEEE Int. Conf. Dielectric Liquids (ICDL), 2014.

29. Maria Martins, "Correction to "Vegetable oils, an alternative to mineral oil for power transformers-experimental study of paper aging in vegetable oil versus mineral oil" , IEEE Electr. Insul. Mag., Vol. 27, Issue: 1, 2011.

30. Maria Martins, "Vegetable oils, an alternative to mineral oil for power transformers- experimental study of paper aging in vegetable oil versus mineral oil", IEEE Electr. Insul. Mag., Vol. 26, Issue: 6, 2010.

31.Md. Amanullah; S. M. Islam; S. Chami; G. Ienco, "Analysis of electro-chemical characteristics of vegetable oils as an alternative source to mineral oil-based dielectric fluid", presented at IEEE Int. Conf. Dielectric Liquids, ICDL 2005.

32.Umar Khayam; Suwarno; Achmad Susilo; Joko Muslim; Yanuar Z. Arief; Masayuki Hikita, "Partial discharge characteristics and dissolved gas analysis of vegetable oil", presented at proc. Of 2014 Int. symp. Electrical Insulating Materials (ISEIM).

33. "Experimental study on vegetable oils properties for power transformer", presented at IEEE conf. Energy Conversion (CENCON), 2015.

34. Yang Xu; Sen Qian; Quanwei Liu; Z. Wang, "Oxidation stability assessment of a vegetable transformer oil under thermal aging", IEEE Trans. Dielectr. Electr. Insul., Vol. 21, Issue: 2, 2014.

35.Henry B. H. Sitorus; Rudy Setiabudy; Setijo Bismo; Abderrahmane Beroual, "Physicochemical and electrical properties of jatrophacurcas methyl ester oil as a substitute for mineral oil”, presented at $18^{\text {th }}$ IEEE Int. Conf. Dielectric Liquids (ICDL), 2014.

36. Yanuar Z. Arief; Mohd Hafizi Ahmad; K. Y. Lau; Nor Asiah Muhamad; Nouruddeen Bashir; Noor Khairin Mohd; Lim Wen Huey; Yeong Shoon Kiat; Shakira Azeehan Azli, "A comparative study on the effect of electrical ageing on electrical properties of palm fatty acid ester (PFAE) and FR3 as dielectric materials", presented at IEEE Int. Conf. Power and Energy (PECon), 2014.

37.I. L. Hosier; A. Guushaa; E. W. Westenbrink; C. Rogers; A. S. Vaughan; S. G. Swingler, "Aging of biodegradable oils and assessment of their suitability for high voltage applications", IEEE Trans. Dielectr. Electr. Insul., Vol. 18, Issue: 3, 2011.

38.U. U. Abdullahi; S. M. Bashi; R. Yunus; Mohibullah; Hj. A. Nurdin, "The potentials of palm oil as a dielectric fluid", presented at IEEE Int. Conf. Power and Energy, PECon 2004. 
39. Shakira A. Azli; Yanuar Z. Arief; Nor Asiah Muhamad; Nouruddeen Bashir, "The effect of electrical ageing on electrical properties of palm fatty acid ester (PFAE) and FR3 as dielectric materials", presented at IEEE stud. Conf. Research and Development (SCOReD), 2013.

40.T. Kano; T. Suzuki; R. Oba; A. Kanetani; H. Koide. "Study on the oxidative stability of palm fatty acid ester (PFAE) as an insulating oil for transformers", presented at Conf. rec. of IEEE Int. Symp. Electrical Insulation (ISEI), 2012.

41.L. Hosier; C. Rogers; A. S. Vaughan; S. G. Swingler, "Ageing behavior of vegetable oil blends", presented at Annu. Report Conf. Electrical Insulation and Dielectric Phenomena (CEIDP), 2010.

42. Md. Amanullah; Syed M. Islam; Sameer Chami; Gary Ienco, "Evaluation of several techniques and additives to de-moisturise vegetable oils and bench mark the moisture content level of vegetable oil-based dielectric fluids", presented at IEEE Int. Conf. Dielectric Liquids, ICDL 2008.

43. S. S. Sinan; S. N. Shawaludin; J. Jasni; Norhafiz Azis; M. Z. A. Ab Kadir; M. N. Mohtar, "Investigation on the AC breakdown voltage of RBD PO Olein”, IEEE Innovative Smart Grid Technologies - Asia (ISGT Asia), 2014.

44.M. Diffni Gomez; N. B. Prakash; B. Vigneshwaran, "Investigation on electrical characteristics of dielectric fluids under aging phenomena", presented at IEEE Int. Conf. Communications and Signal Processing (ICCSP), 2015.

45. S. Arumugam; G. Sriram; V. Santhanam, "Formulation of green crankcase oil - A novel approach", presented at IEEE Int. Conf. Advances in Engineering, Science and Management (ICAESM), 2012.

46. Hans Peter Gasser; Christoph Krause; Mark Lashbrook; Russel Martin, "Aging of pressboard in different insulating liquids", presented at IEEE Int. Conf. Dielectric Liquids (ICDL), 2011.

47.T. V. Oommen; C. C. Claiborne; E. J. Walsh, "Introduction of a new fully biodegradable dielectric fluid", presented at IEEE Textile, Fiber and Film Industry Technical Conf., 1998.

48.R. C. Wicks, "Insulation systems for liquid-immersed transformers - new materials require new methods for evaluation", presented at IEEE Electrical Insulation Conf., EIC 2009.

49. Md. Amanullah; S. M. Islam; S. Chami; G. Ienco, "Analysis of electro-chemical characteristics of vegetable oils as an alternative source to mineral oil-based dielectric fluid", presented at IEEE Int. Conf. Dielectric Liquids, ICDL 2005.

50.R. Eberhardt; H. M. Muhr; W. Lick; B. Wieser; R. Schwarz; G. Pukel, "Partial discharge behaviour of an alternative insulating liquid compared to mineral oil", presented at Conf. rec. of IEEE Int. Symp. Electrical Insulation (ISEI), 2010.

51.R. Eberhardt; H. M. Muhr; W. Lick; B. Wieser; R. Schwarz; G. Pukel, "Partial discharge behaviour of an alternative insulating liquid compared to mineral oil", presented at IEEE Int. Conf. Power Modulator and High Voltage Conference (IPMHVC).

52.Josken; D. Wareham, "Seed based oil as an alternative to mineral oil", presented at IEEE Rural Electric Power Conf., 2004.

53.B. Revathi; M. P. E. Rajamani, "Investigations on the flashover characteristics of ester oil impregnated pressboard under the influence of nanoparticles", presented at IEEE Int. Conf. Electrical, Computer and Communication Technologies (ICECCT), 2015.

54.W. Lick; H. M. Muhr; M. Stössl; R. Schwarz; G. Pukel, "Behaviour of alternative insulating liquids at cold temperatures", presented at Conf. rec. of IEEE Int. Symp. Electrical Insulation (ISEI), 2012.

55. Yann-chang Huang, Huo Ching Sun, "Dissolved gas analysis of mineral oil for power transformer fault diagnosis using Fuzzy logic" IEEE Trans. Dielectr. Electr. Insul. , Vol. 20, No. 03, June 2013.

56.Patrick J. Baird, henrick Herman and Garry C. Stevens, "On Site Analysis of transformer paper insulation using portable spectroscopy for Chemo metric prediction of aged condition”, IEEE Trans. Dielectr. Electr. Insul., vol. 15, No. 4, August 2008.

57.R. V. Radhika; M. Willjuice Iruthayarajan; P. Samuel Pakianathan, "Investigation of critical parameters of mixed insulating fluids", presented at IEEE Int. Conf. Circuit, Power and Computing Technologies (ICCPCT), 2014.

58. Fofana; V. Wasserberg; H. Borsi; E. Gockenbach, "Challenge of mixed insulating liquids for use in high-voltage transformers.1. Investigation of mixed liquids”, IEEE Electr. Insul. Mag., Vol. 18, issue 3, 2012.

59.Loai S. Nasrat; Nesrinekassem; Nadia Shukry (2013), "Aging effect on characteristics of oil impregnated insulation paper for power transformers", Engineering, Version 5.1-7, Jan 2013. [online] Available: http://dx.doi.org/10.4236/eng.2013.51001.

60. A. Masood; M. U. Zuberi and E. Husain, "Breakdown strength of solid dielectrics in Liquid Nitrogen”, IEEE Trans. Dielectr. Electr. Insul., Vol. 15, No.4, August 2008.

61. Shuaiwei Liang; Ruijin Liao; Lijun Yang; Jian Li; Caixin Sun; Huigang Sun, "Thermal aging characteristics of natural ester impregnated Kraft paper and thermally upgraded paper insulation", presented at Int. Conf. High Voltage Engineering and Application, ICHVE 2008. 
62.K. J. Rapp; J. Luksich, "Review of Kraft paper/natural ester fluid insulation system aging”, presented at IEEE Int. Conf. Dielectric Liquids (ICDL), 2011.

63.M. Marci; I. Kolcunová; J. Kurimský, "Dielectric properties of natural esters", presented at $10^{\text {th }}$ Int. Conf. Environment and Electrical Engineering (EEEIC), 2011.

64. Kapila Bandara; Chandima Ekanayake; Tapan Saha; Hui Ma, "Investigation of moisture influence on dielectric response of ester oil impregnated pressboard", presented at Power \& Energy Society General Meeting, IEEE, 2015 .

65.R. Villarroel, Belen Garcia; Diego Garcia; J. Burgos, “Assessing the Use of Natural Esters for Transformer Field Drying”, IEEE Trans. Pow. Del., Vol. 29, Issue 4, 2014.

66.E. Gockenbach; H. Borsi, "Natural and Synthetic Ester Liquids as alternative to mineral oil for power transformers", presented at Annu. Report conf. Electrical Insulation and Dielectric Phenomena, CEIDP 2008.

67. M. Marci; I. Kolcunová, J. Kurimský, "Dielectric properties of natural esters", presented at $10^{\text {th }}$ Int. Conf. Environment and Electrical Engineering (EEEIC), 2011.

68. David A. Trevas; Adam Peterson; Kevin J. Rapp; John Luksich, “Optimal sizing of solar energy transformers using natural ester fluid", presented at $11^{\text {th }}$ Int. Conf. Environment and Electrical Engineering (EEEIC), 2012.

69. Y. V. Thien; N. Azis; J. Jasni; M. Z. A. Ab Kadir; R. Yunus; M. T. Ishak; Z. Yaakub, "Optimal sizing of solar energy transformers using natural ester fluid”, presented at IEEE Int. Conf. Power and Energy (PECon), 2014.

70. Yi Jing; Igor V. Timoshkin; Mark P. Wilson, Martin J. Given; S. J. Mac Gregor; Tao Wang; Jane M. Lehr, "Dielectric properties of natural ester, synthetic ester Midel 7131 and mineral oil diala D", IEEE Trans. Dielectr. Electr. Insul., Vol. 21, Issue: 2, 2014.

71. Kevin J. Rapp; Jerry Corkran; C. Patrick Mcshane; Thomas A. Prevost, "Lightning impulse testing of natural ester fluid gaps and insulation interfaces", IEEE Trans. Dielectr. Electr. Insul. , Vol.16, Issue: 6, 2009.

72.Jean-Claude Duart; Lisa C. Bates, "Aging of high temperature insulation systems with alternative fluids", presented at Conf. Rec. of IEEE Int. Symp. Electrical Insulation (ISEI), 2010.

73. Rafael Villarroel; Belén García; Juan Carlos Burgos; Diego F. García, "Experimental study on moisture dynamics in transformers insulated with natural-esters", presented at IEEE Int. Conf. Solid Dielectrics (ICSD), 2013.

74. A. Abdelmalik; J. C. Fothergill; S. J. Dodd, "Aging of Kraft paper insulation in natural ester dielectric fluid", presented at IEEE Int. Conf. Solid Dielectrics (ICSD), 2013.

75.Imadullah Khan; Zhongdong Wang; Jie Dai; Ian Cotton; Susan Northcote, "Fault gas generation in ester based transformer fluids and dissolved gas analysis (DGA)", presented at IEEE Int. Conf. Condition Monitoring and Diagnosis, CMD 2008.

76. S. Gowthama Kannan; L. Kalaivani; M. Willjuice Iruthayarajan; M. Bakrutheen, "Investigations on critical properties of blended edible natural esters based insulating oil", Circuit, presented at IEEE Int. Conf. Power and Computing Technologies (ICCPCT), 2014.

77.D. Vigneshwaran; M. Ravindran; S. Senthil kumar, "Investigation of critical properties of the highly monounsaturated natural esters with nano composites", presented at IEEE Int. Conf. Innovations in Information, Embedded and Communication Systems (ICIIECS), 2015.

78. Shi-Qiang Wang; Guan-Jun Zhang; Hai-Bao Mu; Da Wang; Min Lei; S. Suwarno; Yuichi Tanaka; Tatsuo Takada, "Effects of paper-aged state on space charge characteristics in oil-impregnated paper insulation", IEEE Trans. Dielectr. Electr. Insul. , Vol. 19, Issue: 6, 2012.

79. Hisashi Morooka; Akira Yamagishi; Hidekazu Miyahara; Hiroyuki Sampei; Masaru Kashiwakura; Yukiyasu Shirasaka, "Compression behaviours of oil-immersed insulating pressed-boards made of Kraft Pulp", IEEE Trans. Dielectr. Electr. Insul. , Vol. 21, Issue: 3, 2014.

80.R. Hollertz; L. Wågberg; C. Pitois, "Effect of composition and Morphology on the dielectric response of cellulose-based electrical insulation", IEEE Trans. Dielectr. Electr. Insul. , Vol. 22, Issue: 4, 2015.

81.M. Aruna.; N. Vasudev; K. N Ravi.; V. V. Pattanshetti, "Novel Insulation system in power transformer", presented at IEEE 10 ${ }^{\text {th }}$ Int. Conf. Properties and Applications of Dielectric Materials (ICPADM), 2012.

82. Maria Augusta G. Martins; A. R. Gomes, "Comparative study of the thermal degradation of Synthetic and Natural Esters and Mineral Oil: Effect of oil type in thermal degradation of insulating Kraft Paper", IEEE Electr. Insul. Mag., Vol. 28, No. 2, pp. 22-28, March/April 2012.

83.B.S.H.M.S.Y. Matharage; M.A.R.M. Fernando (2013), "Performance of Coconut Oil as an alternative transformer liquid insulation”, IEEE Trans. Dielectr. Electr. Insul. , Vol. 20, No. 3, pp. 887-897, June 2013. 
84.R. Eberhardt; H. M. Muhr; W. Lick; B. Wieser; R. Schwarz; G. Pukel, "Partial discharge behaviour of an alternative insulating liquid compared to mineral oil “, presented at IEEE Int. Conf. Power Modulator and High Voltage Conference (IPMHVC), 2010.

85.David A. Trevas; Adam Peterson; Kevin J. Rapp; John Luksich, "Optimal sizing of solar energy transformers using natural ester fluid", presented at $11^{\text {th }}$ IEEE Int. Conf. Environment and Electrical Engineering (EEEIC), 2012.

86.M. Jovalekic; D. Vukovic; S. Tenbohlen, "Gassing behavior of various alternative insulating liquids under thermal and electrical stress", presented at Conf. rec. of IEEE Int. Symp. Electrical Insulation (ISEI), 2012.

87.Pavel Trnka; Václav Mentlík; Michal Svoboda, "Ecologically acceptable insulating liquids for electrical appliances", presented at $18^{\text {th }}$ IEEE Int. Conf. Dielectric Liquids (ICDL), 2014.

88. Maria Augusta G. Martins, "Vegetable Oils, an alternative to mineral oil for power transformers - Experimental study of paper ageing in vegetable oil versus mineral oil", IEEE Electr. Insul. Mag., Vol. 26, No. 6, pp. 7-13, November/December 2010.

89. Yoann Bertrand, "Development of a low viscosity insulating fluid based on vegetable oil", presented at Conf. rec. of IEEE Int. Symp. Electrical Insulation (ISEI), 2012.

90.C. P. Mc Shane, "Relative properties of the new combustion-resist vegetable-oil-based dielectric coolants for distribution and power transformers", IEEE Trans. Ind. Appl., Vol. 37, Issue: 4, 2001.

91.C. P. Mc Shane, "Relative properties of the new combustion resistant vegetable oil based dielectric coolants", presented at $47^{\text {th }}$ Annu. Petroleum and Chemical Industry Conf., Industry Applications Society, 2000.

92.C. P. Mc Shane, "Relative properties of the new combustion resistant vegetable oil based dielectric coolants", presented at Cement Industry Technical Conf., IEEE-IAS/PCA 2001.

93. K. Lee; J. C. Duart; R. Cheng; P. Shieh, "Advanced materials application in fluid-filled transformer", presented at Transmission \& Distribution Conf.\& Exposition: Asia and Pacific, 2009. 